http://jmscr.igmpublication.org/home/ ISSN (e)-2347-176x ISSN (p) 2455-0450

crossref DOI: https://dx.doi.org/10.18535/jmscr/v8i11.56

Journal Of Medical Science And Clinical Research

\title{
A Hospital Based Study of Cardiovascular and Lipid Profile changes in Newly Detected Hypothyroid Patients
}

\author{
Authors \\ Dr G.Sucharitha ${ }^{1}$, Dr.S.Sreenivas ${ }^{2}$, Dr Bongu Sreenivas ${ }^{3}$, Dr M. Bhava Pragna ${ }^{4}$ \\ ${ }^{1,4}$ Post Graduate, Department of General Medicine \\ ${ }^{2}$ Professor, Department of General Medicine \\ ${ }^{3}$ Associate Professor, Department of General Medicine
}

\begin{abstract}
Background and Objectives: Hypothyroidism has significant cardiovascular manifestations. Overt and subclinical hypothyroidism both are associated with cardiovascular dysfunction and with an increased risk of cardiovascular disease. This study was done to recognize cardiovascular changes associated with newly detected hypothyroid patients.

Methods: Based on the symptoms, clinical examination and hormonal assay, newly detected hypothyroid patients were subjected to detailed cardiovascular examination, electrocardiograph, echocardiography and Tread mill test. Patients were investigated, before the thyroid hormone replacement therapy.

Results: Hypothyroidism was newly diagnosed more in females and maximum in age group 18-47 years $(69.9 \%)$ of age group. Out of 30 patients, $63.3 \%$ had symptoms less than 3 months duration. Cardiovascular symptoms was present in less number of patients. Bradycardia was observed in $8 \%$ of the patients. Cardiomegaly was observed in $10 \%$ of the patients. Low voltage complexes in electrocardiogram was present in $43.3 \%$ study group. Pericardial effusion was present in $20 \%$ patients. Tread mill test was positive for inducible ischemia in one patient. Systolic and diastolic dysfunction was noticed respectively in $6.7 \%$ and $3.3 \%$ study group. Altered lipid profile was present in $16.7 \%$ (S. cholesterol) and $53.4 \%$ (S.Triglycerides).

Interpretation and Conclusion: Hypothyroidism is common in females, maximum between 18-47 years age group. Majority of the patients did not have any cardiovascular changes. Observed cardiovascular changes were ECG abnormalities and pericardial effusion. Systematic study was done to know the early effects of hypothyroidism on cardiovascular system. The identification of patients with hypothyroidism is an important individual and public health issue. Hence, early detection and initiation of hormone replacement therapy can minimize associated cardiovascular changes.
\end{abstract}

\section{Introduction}

The most common functional disorder of the thyroid gland is hypothyroidism. It is a clinical state, due to the decreased secretion of thyroid hormones or more rarely, from their impaired activity at tissue level. It is the most common pathological hormone deficiency. Pathology of the thyroid gland (Primary hypothyroidism) accounts for over $99.5 \%$ of cases of thyroid gland failure and $<0.5 \%$ result from disorder of the pituitary gland or hypothalamus(central hypothyroidism). Overt hypothyroidism refers to cases in which the serumthyrotropin (TSH) concentration is elevated and serum T4 (free thyroxine) is below the 
reference range, while subclinical hypothyroidism is defined as an elevated serum TSH value, associated with a serum free $\mathrm{T} 4$ within the reference range. Thyroid hormones have a profound effect on a number of metabolic processes in virtually all tissues and hence virtually every tissues in the body is affected to a greater or lesser extent by thyroid hormone deficiency, the heart being particularly sensitive to its effect. The clinical features dependent on patients age, rate at which hypothyroidism develops. As thyroid hormones are universal determinants of organ function, there may be a multiplicity of symptoms. The cardiovascular risk in hypothyroid patients is related to an increased risk of functional cardiovascular abnormalities. The pattern of cardiovascular abnormalities is similar in subclinical and overt hypothyroidism, suggesting that a lesser degree of thyroid hormone deficiency may also affect the cardiovascular system. It is important to reveal clinical or subclinical thyroid diseases in time for the effective treatment and for stopping of the cardiovascular damages before manifestation of cardiovascular system. Hypothyroidism is treated by hormone replacement therapy; which is simple, affordable and effective.

\section{Objectives}

1. To study all the cardiovascular changes associated in newly detected hypothyroidism.

2. To know the cardiovascular involvement in sub-clinical hypothyroidism. To know the benefits of early diagnosis and correction of hypothyroidism in minimizing cardiovascular effects.

\section{Methodology}

\section{Source of data}

Thirty cases of newly detected primary hypothyroidism were studied from Feb2019 to Feb 2020. Data was collected from thirty patients both outpatient and inpatient in this period, treated at King George Hospital, Visakhapatnam. Those patients who were found or suspected to be suffering from hypothyroidism on clinical evaluation and confirmed by serum $\mathrm{TSH}, \mathrm{T} 4$ and T3 levels estimation were taken for the study.

\section{Method of Collection of Data}

The data for the purpose of the study was collected in a predesigned and pretested proforma which include various socioeconomic parameters like age, sex, occupation, religion etc. About 30 cases were selected on the basis of the simple random sampling method. The analysis of data was made on the basis of the important statistical parameters like the mean deviation, standard error, the t-test and the proportion test. All the values were compared at $5 \%$ or 0.05 and $1 \%$ or 0.01 levels of significances for the corresponding degrees of the freedom.

\section{Inclusion Criteria}

All the cases of newly detected hypothyroidism diagnosed by clinical evaluation and confirmed by serum TSH, total T4 and Total T3 level.

\section{Exclusion criteria}

1) Secondary hypothyroidism cases

2) Hypothyroidism patients who are already on treatment since long time. Significant intake of drugs like beta-blockers, alcohol, oral-pills, amiodarone, glucocorticoids and antineoplastic drugs.

3) Patients with other associated diseases like diabetes, hypertension, pernicious anaemia, collagen disorders, primary cardiac disorders and other endocrine disorders (hypoparathyroidism, hypogonadism, etc) and pregnancy.

The patients included in the study were examined in detail and necessary investigations were conducted and the data recorded in the proforma. 


\section{Investigations}

The following investigations were done to diagnose the hypothyroidism (newly detected) and with associated cardiac profile.

1) Serum T3, T4, TSH.

2) Estimation of FT3 and FT4 (if indicated)

3) Lipid profile

4) Chest X-ray

5) Electro cardiogram

6) Echocardiogram

7) Tread Mill test

\section{Results}

This study was conducted at King George Hospital, Visakhapatnam for a period between February, 2019 to February, 2020. Thirty cases of newly detected hypothyroidism were selected for the study, after applying inclusion and exclusion criteria shown in the materials and methods. The observations and results of the study are presented here.

\section{Thyroid profile}

Table 1: Different ranges of serum TSH levels in the study group $(n=30)$

\begin{tabular}{|l|c|c|c|c|c|c|c|c|c|}
\hline $\begin{array}{l}\text { Sl. } \\
\text { No. }\end{array}$ & $\begin{array}{c}\text { TSH } \\
(\mu \mathbf{I U} / \mathbf{m l})\end{array}$ & Male & $\boldsymbol{\%}$ & Female & $\boldsymbol{\%}$ & Total & $\boldsymbol{\%}$ & $\begin{array}{c}\text { value } \\
\mathbf{p}-\end{array}$ & Inference \\
\hline 1 & $<29$ & 0 & 0 & 4 & 17.4 & 04 & 13.3 & $<0.05$ & $\mathrm{~S}$ \\
\hline 2 & $30-49$ & 0 & 0 & 4 & 17.4 & 04 & 13.3 & $<0.05$ & $\mathrm{~S}$ \\
\hline 3 & $50-69$ & 06 & 85.7 & 9 & 39.1 & 15 & 50.0 & $<0.05$ & $\mathrm{~S}$ \\
\hline 4 & $70-89$ & 0 & 0 & 01 & 4.3 & 01 & 3.3 & - & - \\
\hline 5 & $90-109$ & 01 & 14.3 & 03 & 13.1 & 04 & 13.4 & - & - \\
\hline 6 & $>109$ & 0 & 0 & 02 & 8.7 & 02 & 6.7 & - & - \\
\hline Total & 07 & 100 & 23 & 100 & 30 & 100 & & & \\
\hline
\end{tabular}

Table 2: Different ranges of T4 levels

\begin{tabular}{|l|c|c|c|c|c|c|c|}
\hline Sl. No. & T4 $(\mu \mathbf{g} / \mathbf{d l})$ & Male & $\mathbf{\%}$ & Female & \% & Total & \% \\
\hline 1 & $<1.0$ & 05 & 71.4 & 06 & 26.1 & 11 & 36.7 \\
\hline 2 & 1.1 to 2.0 & 01 & 14.3 & 07 & 30.4 & 08 & 26.7 \\
\hline 3 & 2.1 to 4.0 & 01 & 14.3 & 06 & 26.1 & 07 & 23.3 \\
\hline 4 & 4.1 to 6.0 & 0 & 0 & 04 & 17.4 & 04 & 13.3 \\
\hline Total & 07 & 100 & 23 & 100 & 30 & 100 & \\
\hline
\end{tabular}

Mean : 1.9 SD : $1.5 \mathrm{p}>0.05$ (NS)

In the present study the diagnosis was confirmed on the basis of serum TSH and serum T4 levels. $50 \%$ of the patients had serum TSH level between $50-59 \mu \mathrm{IU} / \mathrm{ml} .16 .7 \%$ of the patients were in the range of 70 to $109 \mu \mathrm{IU} / \mathrm{ml}$ and $6.7 \%$ in the range of above $109 \mu \mathrm{IU} / \mathrm{ml}$. The majority of the patients (36.7\%) had serum $\mathrm{T} 4$ level below $1 \mu \mathrm{g} / \mathrm{dL}$ and $26.7 \%$ between 1.1 to $2 \mu \mathrm{g} / \mathrm{dL}$

\section{Lipid profile}

Increased levels of serum cholesterol, especially LDL cholesterol and are increased levels of serum triglycerides are constantly associated with hypothyroidism.

In the present study 7 patients $(23.3 \%)$ had border line high cholesterol level,5 patients (16.7\%) had high serum cholesterol levels. 18 patients $(60 \%)$ had normal serum level. Serum triglycerides was high in 16 patients $(53.4 \%)$ and in 10 patients (33.3\%) had border line high levels. In 4 patients it was in the normal range. 3 patients (10\%) had high LDL levels, 2 patients $(6.7 \%)$ had borderline high levels. 8 patients $(26.6 \%)$ are in the near optimal levels. 17 patients $(56.7 \%)$ were in the optimal serum LDL levels. Serum HDL-C was high in 6 patients $(20 \%)$. The majority of the patients $(56.7 \%$ ) it was between $40-60 \mathrm{mg} / \mathrm{dL}$. In 7 patients $(23.3 \%)$ HDL was low. 


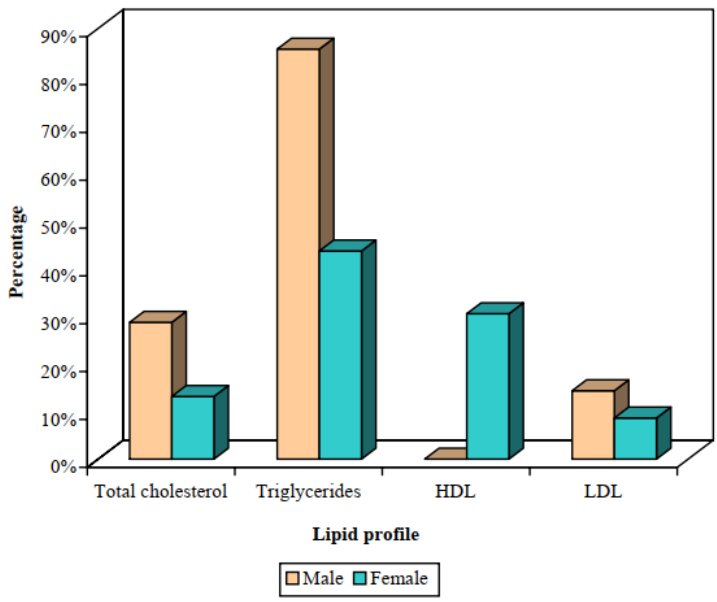

\section{Radiology}

Cardiomegaly on chest x-ray was seen in one male patient $(14.3 \%)$ and two female patients $(8.6 \%)$. Thus only 3 of the 30 patients in the study group (10\%) showed cardiomegaly.

\section{Electrocardiogram (ECG)}

Low voltage complexes in the ECG are one of the characteristic features of hypothyroidism. In this study 10 female patients out of 23 showed low voltage complexes (43.4\%). 3 male patients out of 7 had low voltage complexes $(42.9 \%)$.

Thus in total, $43.3 \%$ of patients (13 out of 30 ) low voltage. QRS complexes in the ECG in the present study.

\section{Echocardiogram}

Pericardial effusion was found in 2 male patient out of 7 male patients (28.6) and in 4 out of twenty three female patients (i.e 17.3\%) in total, pericardial effusion was seen in 6 patients out of thirty patients i.e. $20 \%$ in the study group. Out of these 6pericardial effusions 4 were small effusions, 2 were moderate effusions at the time of examination.

Out of 30 patients 2 patients $(6.7 \%)$ had systolic dysfunction that is 1 male and 1 female. $3.3 \%$ had diastolic dysfunction.

\section{Tread mill study}

Only 26 patients was included for TMT study 4 patients were deferred due to osteoarthritis, effort intolerance. 1 male patient $(14.3 \%)$ was positive in the study.

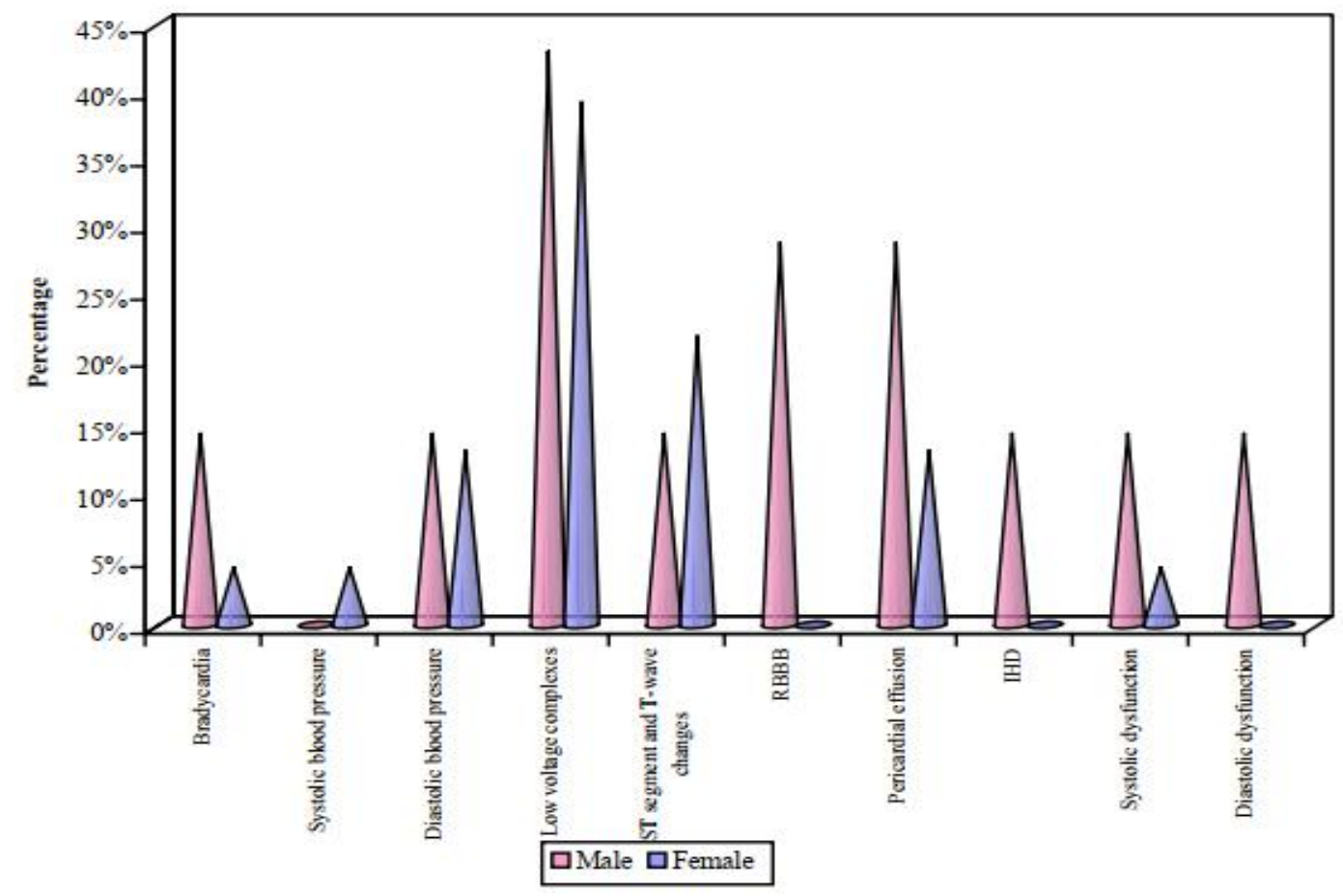




\section{Discussion}

During the study period thirty cases of hypothyroidism were newly detected.

Out of which 23 were females and 7 male patients.

These patients were studied with history, clinical signs and symptoms and investigated and recorded in the proforma and the following observations were made and compared with other studies.

Table 3: Comparative study of ECG changes low voltage complexes

\begin{tabular}{|c|c|c|c|}
\hline $\begin{array}{c}\text { Watanakunakom et al } \\
(\mathbf{1 9 6 5 )})^{\mathbf{1 3}}\end{array}$ & liam F.C. et al (1977) $)^{\mathbf{1 2}}$ & Tajiri J. et al (1985) & Present study \\
\hline $36.25 \%^{*}$ & $40 \% *$ & $32.14 \%$ & $43.3 \%$ \\
\hline
\end{tabular}

The present study correlates with the incidence reported by William FC et al.

Table 4: Table showing various ECG changes in the present study

\begin{tabular}{|c|c|c|c|c|}
\hline Bradycardia & $\begin{array}{c}\text { Low voltage } \\
\text { complexes }\end{array}$ & $\begin{array}{c}\text { PR interval } \\
0.2 \mathrm{sec}\end{array}$ & ST-T changes & Others RBBB \\
\hline $8 \%$ & $43.3 \%$ & $6.6 \%$ & $23.3 \%$ & $6.6 \%$ \\
\hline
\end{tabular}

In the present study the most common ECG manifestation was low voltage complexes (43.3\%), followed by ST-T changes (23.3\%).
Bradycardia was found in $8 \%$ of the patients and upper limit of PR interval was found in $6.6 \%$ of the patient. RBBB was found in $6.6 \%$.

Table 5: Table showing percentage of patients with pericardial effusion (PE) in different studies

\begin{tabular}{|c|c|c|c|c|}
\hline abadi et al (1990) $^{\mathbf{I 1}}$ & arma et al (1995) $^{\mathbf{6}}$ & $\begin{array}{c}\text { Gupta M.M. et al } \\
\mathbf{( 2 0 0 0 )}^{\mathbf{7}}\end{array}$ & $\begin{array}{c}\text { Saritha Bajaj et al } \\
\mathbf{( 2 0 0 2 )}^{\mathbf{8}}\end{array}$ & Present study \\
\hline $3-6 \%^{*}$ & $22.75 \% *$ & $15 \%$ & $30.3 \%$ & $20 \%$ \\
\hline
\end{tabular}

The incidence of pericardial effusion in the present study correlates with the incidence reported by $\mathrm{R}$ Varma et al.

Table -6: Comparative study of cardiomegaly on X-ray chest

\begin{tabular}{|l|c|c|}
\hline & Akthar M et al (1978) & Present study \\
\hline Cardiomegaly on $\mathrm{x}-\mathrm{ray}(\mathrm{n}=30)$ & $5.6 \%$ & $3 / 3010 \%$ \\
\hline
\end{tabular}

Table 7: Comparative study of Lipid Profile

\begin{tabular}{|c|c|c|c|c|c|c|}
\hline \multirow{2}{*}{$\begin{array}{c}\text { Lipid Profile } \\
(\mathbf{m g} / \mathbf{d l})\end{array}$} & \multicolumn{2}{|c|}{ A Gupta et al (1996) } & \multicolumn{2}{c|}{ S.K. Rajan (2003) } & \multicolumn{2}{c|}{ Present study } \\
\cline { 2 - 7 } & Mean & SD & Mean & SD & Mean & SD \\
\hline Cholesterol & 231.27 & 68.30 & 235.5 & - & 206.7 & 30.9 \\
\hline Triglycerides & 235.59 & 137.53 & 166.3 & - & 206.2 & 50.78 \\
\hline LDL & 126.09 & 54.09 & 145.0 & - & 108.63 & 28.17 \\
\hline HDL & - & - & 46.3 & - & 54.12 & 6.26 \\
\hline
\end{tabular}

Mean serum lipid levels in the two studies are fairly comparable.

\section{Conclusion}

1) The hypothyroid patients present clinically with a myriad of symptoms and signs which are nonspecific. Hence a high index of suspicion is the key for the early diagnosis of hypothyroidism.

2) Cardiovascular changes are less commonly associated with newly detected hypothyroidism.
3) Pericardial effusion occurs in a low percentage of newly detected hypothyroid patients.

4) The occurrence of pericardial effusion in hypothyroidism is significantly related to the duration of the disease; hence the need for early diagnosis of hypothyroidism. 
5) There is no relation between thyroid profile and occurrence of pericardial effusion in hypothyroid patients.

6) X-ray chest is not a reliable tool of the diagnosis of pericardial effusion. Hence echocardiogram is the investigation of choice for the diagnosis of pericardial effusion.

7) Altered lipid profile was found in the hypothyroid patients.

8) The identification of hypothyroid patients is an important individual and public health issue.

9) Early diagnosis and correction of hypothyroidism is necessary; so that early effects on cardiovascular system can be minimized.

\section{References}

1. Boelaert K, Franklyn JA. Thyroid hormone in health and disease. $\mathrm{J}$ Endocrinol2005; 187(1) : 1-15.

2. Caroline GP Roberts, Paul W. Ladenson. Hypothyroidism. Lancet 2004; 363 :793803.

3. Kerber E, Richard, Barry S. Echocardiographic Evaluation of Pericardial Effusion in Myxoedema. Circulation 1975; 52: 823-827.

4. Reed Larsen P, Terry F Davies, Ian D Hay. Thyroid physiology andDiagnostic evaluation of patients with thyroid disorders, Chapter 10, andHypothyroidism and Thyroiditis, Chapter 12, Williams Text book of Endocrinology, 10th Edition. W.B. Saunders Company 2003; 331355,423-446.

5. Serafino Fazio, Emiliano A. Palmieri, et al. Effects of Thyroid Hormone onthe cardiovascular system. Recent progress in Hormone Research 2004; 59:31-50.

6. Varma R, Jain AK, Ghose T, et al. Heart in hypothyroidism. An echocardiographic study. JAPI 1996; 44(6): 390-392.
7. Gupta MM, Doomra M, et al. Heart in hypothyroidism : an Echocardio graphic study. JAPI 2001; 49: 141.

8. Saritha Bajaj, Saxena PC, Sharma GP, et al. Cardiovascular Assessment of hypothyroidism before and after treatment. IJEM 2003; V(1): 23-30.

9. Akthar M, Singh SJ, Krishnamurthi S. Cardiovascular Manifestations in Thyroid Disorders. Indian Heart Journal 1978; 30(4):203-7.

10. Tajiri $\mathrm{J}$, et al. Lactate dehydrogenase isozyme and hypothyroidism. Arch Intern Med 1985; 145(10): 1929-30.

11. Kabadi M Udaya, Samuel P Kumar. Pericardial Effusion in Primary Hypothyroidism. American Heart Journal 1990; 120(6): 1393-1395.

12. Crowley F, Willam et al. Noninvasive evaluation of cardiac function in hypothyroidism. The New England Journal of Medicine 1977; 296: 1-6.

13. Watanakunakorn C, Robert EH, Titus CE. Myxoedema. Arch Intern Med 1965; 116: 183-89. 